\title{
Neonatal Empyema Thoracis
}

\author{
Mazumdar $\mathrm{J}^{1}$, Sen $\mathrm{S}^{2}$
}

\begin{abstract}
Empyema thoracis, is a rare cause of respiratory distress in neonates. Only a few cases of neonatal empyema thoracis are described in medical literature. Empyema thoracis is not a well known entity in the neonates. It is fulminant with rapid progression with a high mortality. Compounding the problem is its uncertain etiopathogenesis and lack of definite treatment guidelines. We shall describe one case of neonatal empyema in a newborn aged five days caused by Pseudomonas aeruginosa. The neonate died subsequently.
\end{abstract}

Key words: Empyema, Neonate.

\section{Introduction}

$\mathrm{E}^{\mathrm{m}}$ mpyema thoracis is defined as pyogenic infection of pleural cavity with accumulation of pus in the pleural space which can be diffuse or loculated ${ }^{1}$. Empyema is frequenty seen in infants and children of pre-school age and it occurs in 5-10 per cent children with bacterial pneumonia ${ }^{1}$.Yet reports are scanty as far as neonatal period is concerned. We are presenting a case of neonatal empyema which has occurred in our hospital's newborn unit.

\section{The Case}

A full term female baby weighing $2.5 \mathrm{~kg}$, born of normal vaginal delivery to a primigravida, presented to our hospital with chief complaints of refusal to suck and yellowish discoloration of whole body up to the sole on the second day. There was history of premature rupture of membranes $24 \mathrm{hrs}$ prior to delivery. Her total bilirubin was $19.6 \mathrm{mg} / \mathrm{dl}$ (conjugated $1.5 \mathrm{mg} / \mathrm{dl}$, unconjugated $18.1 \mathrm{mg} / \mathrm{dl}$ ). On the day of admission $\mathrm{Hb}$ was $16.5 \mathrm{gm} \%$, TLC 4700/ $\mathrm{cmm}$, Platelet count $130000 / \mathrm{cmm}$. On the day of admission, she was put under double surface phototherapy and blood culture was sent prior to start of intravenous antibiotics (cefotaxime and amikacin according to our local practice guidelines). On day 5, she developed respiratory distress and fast breathing (RR 70/min). Chest radiograph revealed a consolidation in right lower zone. Antibiotics were changed from cefotaxim, amikacin to meropenem and vancomycin after considering the blood culture reports done by BACTEC methods. In next $48 \mathrm{hrs}$ there was no improvement, and there were absent breath sounds in whole right lung. Chest X-ray
'Dr. Jayitri Mazumdar, MBBS, MD Resident, ${ }^{2} \mathrm{Dr}$. Sandip Sen, MBBS, MD Associate Professor. Both from the Department of Paediatrics, Calcutta National Medical College and Hospital, Kolkata, India.

\section{Address for correspondence}

Dr. Jayitri Mazumdar

E-mail: jayidoc@gmail.com

\section{How to cite}

Mazumdar J, Sen S. Neonatal Empyema Thoracis. J Nepal Paediatr Soc 2014;34(1):65-67.

doi: http://dx.doi.org/10.3126/jnps.v34i1.8233

This work is licensed under a Creative Commons Attribution 3.0 License.

(c) (i)

showed diffuse right sided opacity with shifting of mediastinum to left (Fig.-1).

Pleural tap revealed thick pus and thoracostomy done with 8 FG portex radio opaque thoracic cannula, at $6^{\text {th }}$ intercostal space in mid axillary line (Fig. 2 and 3). Chest drain was inserted on the seventh day. Blood culture revealed growth of Pseudomonus aeruginosa sensitive to meropenem and cefepime. Pleural fluid showed a cell count of $1,10,000$ /cumm, $98 \%$ neutrophils, and pleural fluid culture showed no growth up to $48 \mathrm{hrs}$.

Pus amounting to $200 \mathrm{ml}$ was drained out in first $48 \mathrm{hrs}$. Peripheral smear revealed toxic granules and band cells with $\mathrm{a} \mathrm{Hb}$ $15 \mathrm{gm} \%$, TLC 3400/cumm and a platelet count of $80000 / \mathrm{cmm}$. The chest drain was 
removed after 7 days as no further collection was noted and the baby was treated with appropriate antibiotic (meropenem) for 21 days. But gradually she developed oedema of whole body and oliguria (serum albumin was 2,2 gm/dl), and serum urea creatinine were $54 \mathrm{mg} /$ $\mathrm{dl}$ and $1.2 \mathrm{mg} / \mathrm{dl}$ respectively on day 18 and peritoneal dialysis was instituted. Four units of FFP transfused and bolus doses of normal saline followed by diuretics were given. But urine output gradually worsened along with increasing urea and creatinine values $(68 \mathrm{mg} / \mathrm{dl}$ and $1.5 \mathrm{mg} / \mathrm{dl}$ on day 21). Baby ultimately died on the $22^{\text {nd }}$ day probably due to acute renal failure along with septicemia.

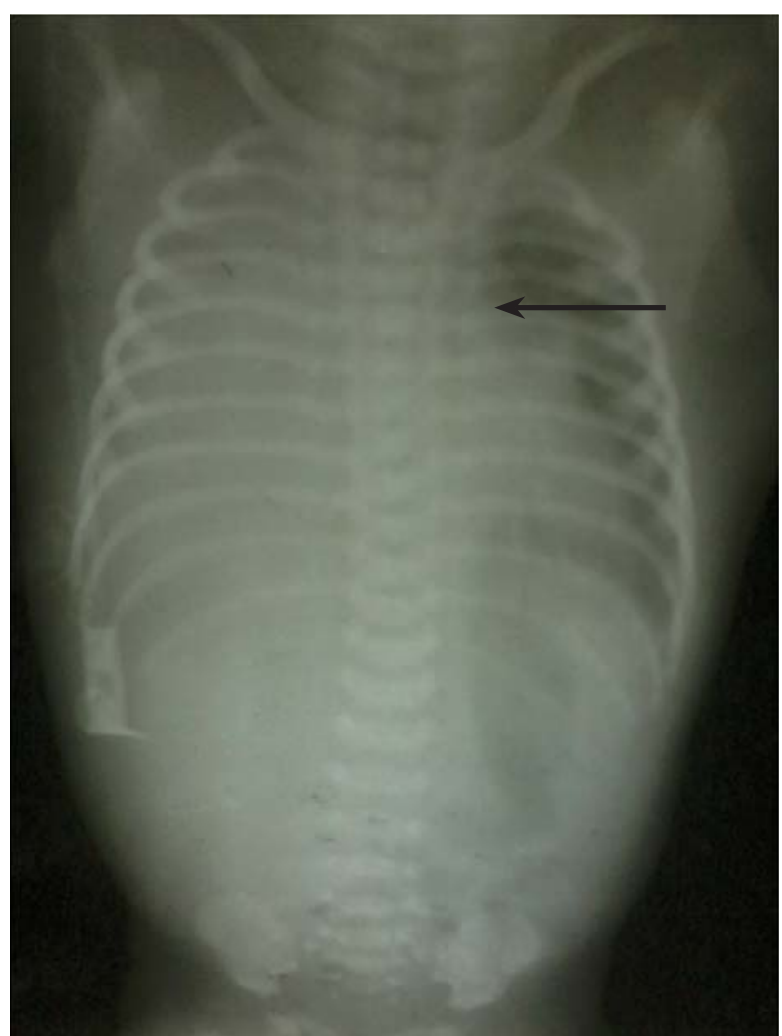

Fig 1: Chest X-ray showing right-sided diffuse opacity with shifting of mediastinum

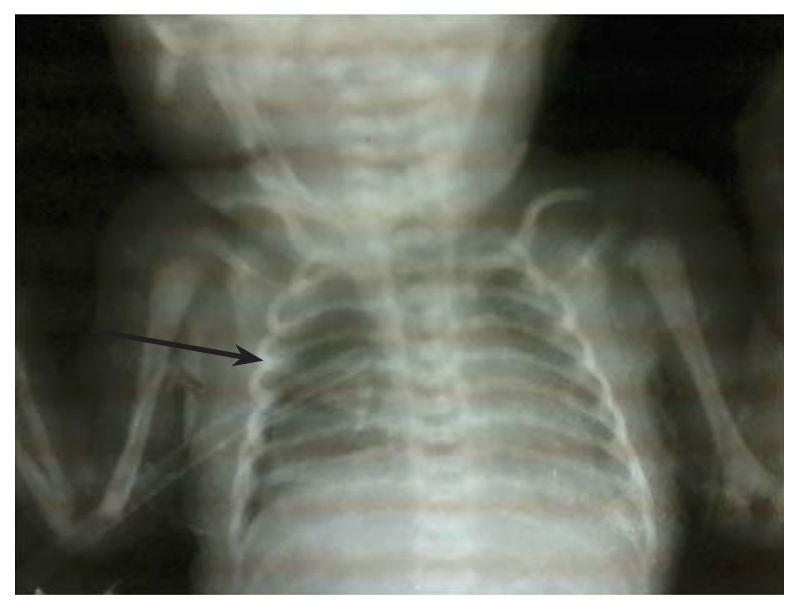

Fig. 2: Chest X-ray showing thoracostomy tube in right lung and clearance of previous opacity

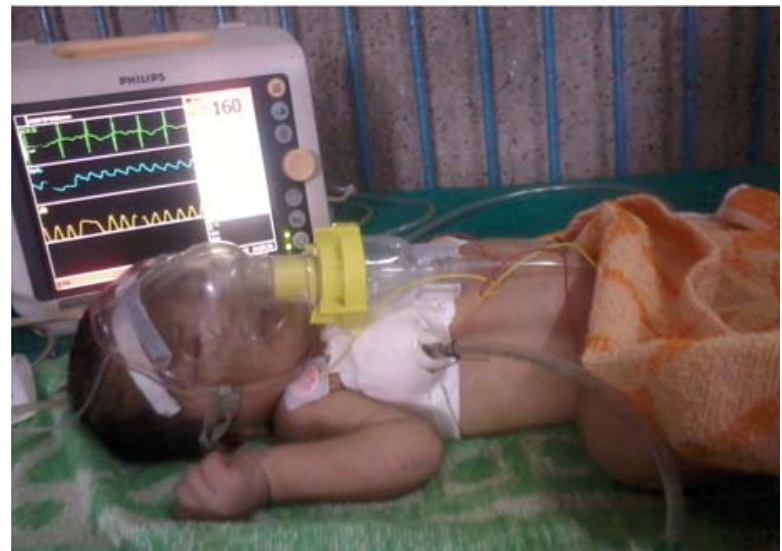

Fig 3: Baby with thoracostomy tube in situ

Although pleural empyema is seen frequently in children,it is very uncommon in neonates ${ }^{2,3}$. The most common causative organisms in pleural empyema in neonates are S.aureus, E.coli, Klebsiella, haemolytic GroupB streptococcus, haemolytic Group A streptococcusand Serratia $s p^{4,5}$.

Despite of being an infrequent nosocomial pathogen in neonates, empyema thoracis due to $P$. aeruginosa is very very uncommon and the mortality rate is very high ${ }^{6,7,8}$.

$P$. aeruginosa is a motile, aerobic, gram negative bacillus with the ability for local invasion, production of virulent factors and dissemination due to the presence of pili, fimbriae on the surface of the organism. Some strains can produce biofilm containing a mucoid polysaccharide called alginate which makes them less susceptible to antimicrobials. Furthermore, Exotoxin $A$ and Exoenzyme $S$ are the products produced by pseudomonas which are responsible for the development of sepsis syndrome by the organism ${ }^{9}$. The organism also produce plasmid associated beta lactamases which render the organism multidrug resistant.

We found only few cases of neonatal empyema described in the medical literature. It is a rare entity in the neonatal period. Experience in the management of neonatal empyema is lacking and no standard protocol is currently available.

In addition to the intravenous antibiotics, therapeutic options for paediatric empyema thoracis include tube drainage (for up to 1 week), tube drainage and intrapleural fibrinolysis and surgical drainage (via video assisted thoracostomy (VATS) or thoracotomy. Many articles showed superiority of VATS over other treatment options in different outcome measures, including failure, length of fever, length of intravenous treatment and hospital stay ${ }^{10}$. 


\section{References}

1. WinnieGB, LossefSV,Purulent Pleurisyor Empyema. In Kliegman.Stanton,St. Geme,Schor,Behrman, Nelson Textbook of Paediatrics; 19 ${ }^{\text {th }}$ Edition,2011, Philadelphia Saunders Elsevier,Pg 1507

2. Khan EA, Wafelman LS, Garcia-Prats JA, Tabe LH. Serratia marcescens pneumonia, empyema and pneumatocele in a preterm neonate. Pediatr Infect Dis J 1997;16:1003-5.

3. Nathavitharana KA, Watkinson MA. Neonatal pleural empyema caused by group A Streptococcus. Pediatr Infect Dis J 1994;13:671-2.

4. Shen YH, Hwang KP, Niu CK. Compl icated parapneumonic effusion and empyema in children. J Microbiol Immunol Infect 2006;39:483-8.

5. Sokal MM, Nagraj A, Fisher BJ, Vijayan S. Neonatal empyema caused by group B beta hemolytic streptococcus. Chest 1982;81:390-1.
6. Ortega B, Groeneveld J. Endemic multidrugresistant Pseudomonas aeruginosa in critically ill patients. Infect Control Hosp Epidemiol 2004;25:825-31.

7. Moolenaar RL, Crutcher JM, San Joaquin VH, et al. A prolonged outbreak of Pseudomonas aeruginosa in a neonatal intensive care unit: did staff fingernails play a role in disease transmission? Infect Control Hosp Epidemiol 2004;21:80-5.

8. Lautenbach $\mathrm{E}$, Weiner MG, Nachamkin I, Bilker WB, Sheridan A, Fishman NO. Imipenem resistance among Pseudomonas aeruginosa isolates: risk factors for infection and impact of resistance on clinical and economic outcomes. Infection Control Hosp Epidemiol 2006;27: 893-900.

9. Zafar $A B$, Sylveste aeruginosa infections in a neonatal care unit. Am J Infect Control 2002;30:425

10. Wong KS et al, Taiwan. Scoring system for empyema thoracis and help in management. Indian J Pediatr 2006;72:1025-8. 